\title{
Complete Restored Hearing Loss after Excessive Nose Blowing with Various CT Findings
}

\author{
Ji Hoon $\mathrm{Koh}^{1,2} \mathbb{D}$ and Eun Jung Lee ${ }^{1,2}$ (D) \\ ${ }^{1}$ Department of Otorhinolaryngology-Head and Neck Surgery, College of Medicine, Jeonbuk National University, Jeonju; and \\ ${ }^{2}$ Research Institute of Clinical Medicine of Jeonbuk National University-Biomedical Research Institute \\ of Jeonbuk National University Hospital, Jeonju, Korea
}

\author{
과도한 코풀기 이후 발생한 난청의 완전 회복을 보인 증례들과 다양한 CT 소견들 \\ 고지훈 ${ }^{1,2} \cdot$ 이은정 ${ }^{12}$ \\ 전북대학교 의과대학 이비인후-두경부외과학교실, ${ }^{1}$ 전북대학교 임상의학연구소-전북대학교병원 의생명연구원 ${ }^{2}$
}

\author{
Received June 30, 2020 \\ Revised August 29, 2020 \\ Accepted September 14, 2020 \\ Address for correspondence \\ Eun Jung Lee, MD, PhD \\ Department of Otorhinolaryngology- \\ Head and Neck Surgery, \\ College of Medicine, \\ Jeonbuk National University, \\ 20 Geonji-ro, Deokjin-gu, \\ Jeonju 54907, Korea \\ Tel $+82-63-250-1980$ \\ Fax $+82-63-250-1986$ \\ E-mailimaima97@naver.com
}

A perilymphatic fistula (PLF) is defined as leakage of perilymph with several possible causes such as superior canal dehiscence through trauma, temporal bone fracture, or sudden pressure change (e.g., skydiving or scuba diving). Pneumolabyrinth can result from temporal bone fracture after trauma, or sudden pressure change in the middle ear or cerebrospinal fluid, such as excessive nose blowing or Valsalva maneuver. A PLF and pneumolabyrinth may occur without trauma, associated with a sudden pressure change in the middle ear. We report two cases of PLF followed by pneumolabyrinth and one case of suspicious PLF without pneumolabyrinth after excessive nose blowing. All three cases were diagnosed as having sensorineural hearing loss and the patients recovered completely after conservative treatment. We report various CT findings of pneumolabyrinth and PLF, from normal CT findings to air pockets in the labyrinth and soft tissue density around the stapes.

Korean J Otorhinolaryngol-Head Neck Surg 2020;63(12):620-4

Key Words Barotrauma · Hearing loss, sensorineural · Perilymph · Sneezing ·

Temporal bone.

\section{Introduction}

A perilymphatic fistula (PLF) is a phenomenon defined as leakage of perilymph through the oval window or round window. ${ }^{1)}$ The perilymph is located in the bony labyrinth and the bony labyrinth encloses the membranous labyrinth which contains endolymph. When the two different types of lymphatic fluid are mixed or there is a leakage of lymphatic fluid into the middle ear cavity through an abnormal track, this is also called a PLF. Generally, lymphatic fluid leakage due to superior canal dehiscence or dehiscence of the semicircu-

This is an Open Access article distributed under the terms of the Creative Commons Attribution Non-Commercial License (https://creativecommons.org/licenses/by-nc/4.0) which permits unrestricted non-commercial use, distribution, and reproduction in any medium, provided the original work is properly cited. lar canal after cholesteatoma is not considered to be a PLF. ${ }^{2)}$ As reported in many cases, a PLF can be a result of head trauma or an external impact causing a temporal bone fracture. There are several reports indicating that PLF can occur without trauma, for example, after a Valsalva maneuver. Barotrauma such as forceful sneezing, nose blowing, skydiving or scuba diving causing a sudden pressure change are regarded as other causes of PLF. Leakage of perilymph can occur through the oval or round window membrane, fissula ante fenestram, microfissures, or Hyrtl's fissure. ${ }^{3-5)}$

Pneumolabyrinth is a condition where air accumulates in the inner ear space such as the vestibule or cochlea through an abnormal track or passage. Increased pressure in the middle ear cavity, after a certain event, will push air from the mid- 
dle ear into the inner ear through an abnormal passage which in this case is a PLF and can cause inner ear symptoms such as dizziness and hearing impairment. The usual cause is thought to be temporal bone fracture after trauma followed by pressure change, especially PLF after a fracture violating the otic capsule. ${ }^{\text {() }}$ However, pneumolabyrinth may occur without trauma. ${ }^{7)}$ Pressure change in the middle ear or cerebrospinal fluid (CSF) is considered to be another typical cause of pneumolabyrinth, and excessive nose blowing or Valsalva maneuver can increase the middle ear or CSF pressure.

We report three cases of complete recovery of hearing loss caused by a PLF followed by pneumolabyrinth after nose blowing and without trauma. In all cases, the patients' symptoms resolved spontaneously after conservative treatment. We also review the possible mechanisms of PLF formation.

This study was reviewed and approved by the Institutional Review Board (CUH 2020-02-043).

\section{Case}

\section{Case 1}

A 15-year-old female patient presented with hearing loss and vertigo after excessive nose blowing. This had commenced 2 days before visiting our department. Associated symptoms were nausea, tinnitus and fullness of the left ear. Otoscopic examination identified an intact eardrum. Vestibular function tests including spontaneous and gaze nystagmus test, and positional and positioning nystagmus test were normal. Pure tone audiometry indicated a threshold of $22 \mathrm{~dB}$ for both bone and air conduction of the left ear (Fig. 1A). As the clinical symptoms were suggestive of a PLF, a high resolution temporal bone CT scan was performed and this showed multiple air pockets in the left vestibule (Fig. 2A). As a result, she was diagnosed as having a PLF with pneumolabyrinth and was admitted to our clinic. A high-dose steroid was administered along with broad-spectrum antibiotics. The patient's dizziness and nausea symptoms resolved gradually with improvement in hearing. Pure tone audiometry 8 days after admission had improved to $8 \mathrm{~dB}$ for air conduction and $5 \mathrm{~dB}$ for bone con-
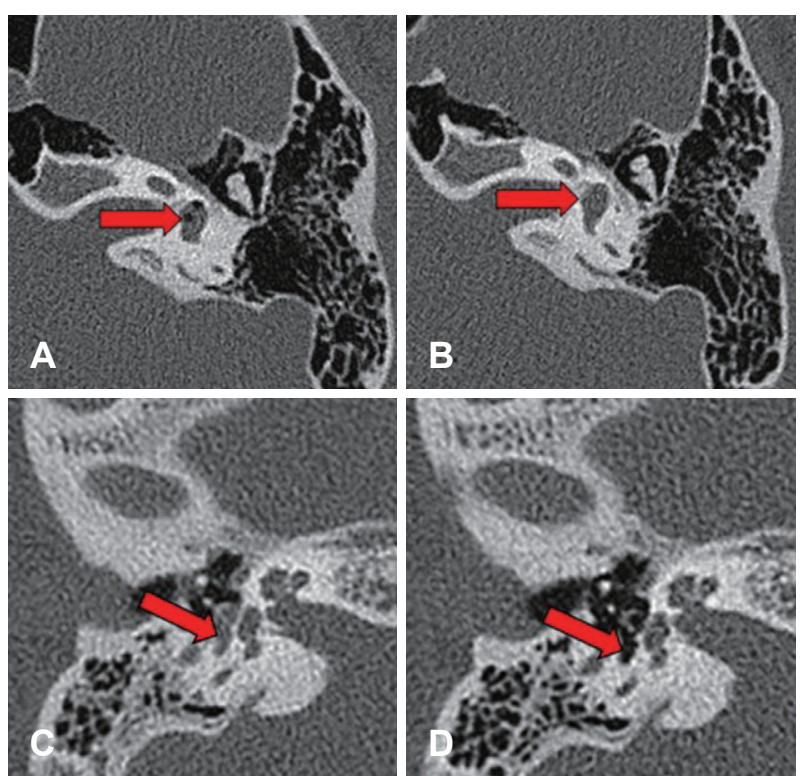

Fig. 2. Temporal bone CT of case 1, after admission. Multiple air pockets around the left vestibule (arrow, A). Temporal bone CT of case 1, after treatment. Air pockets had disappeared (arrow, B). Temporal bone CT of case 2, after admission. Soft tissue density around the stapes, indicating suspected perilymphatic fistula (arrow, C). Temporal bone CT of case 2, after treatment. Soft tissue density had disappeared (arrow, D).
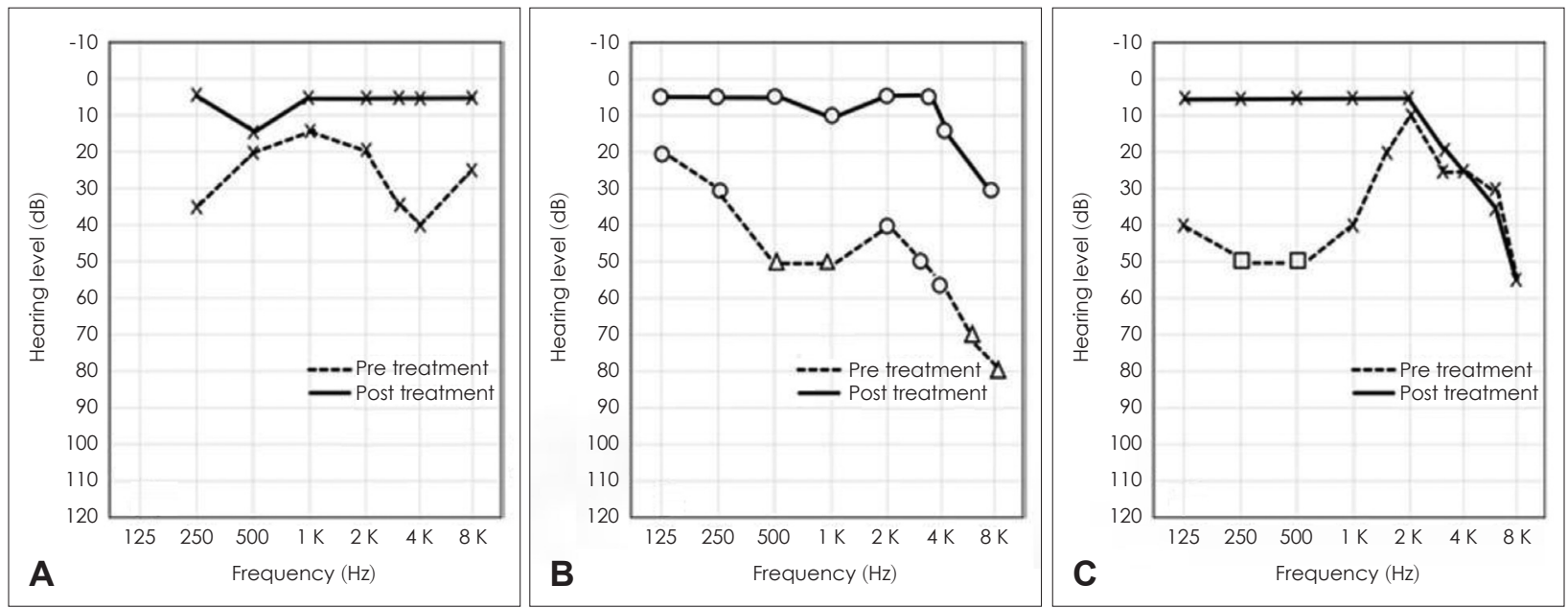

Fig. 1. Case 1: pure tone audiometry (air conduction) follow up since admission to hospital day 8 (A). Case 2: pure tone audiometry (air conduction) follow up since admission to 3 months (B). Case 3: pure tone audiometry (air conduction) follow up since admission to 3 months (C). $\times$ : air conduction (left), $\bigcirc$ : air conduction (right), $\square$ : air conduction (left, masking), $\triangle$ : air conduction (right, masking). 
duction threshold (Fig. 1A). A follow-up high resolution temporal bone CT scan was performed 8 days after admission (Fig. 2B). The multiple air pockets in the left vestibule had disappeared and the patient was discharged (Table 1).

\section{Case 2}

A 59-year-old female patient visited our department with sudden onset vertigo and hearing loss. She had blown her nose excessively 6 days earlier, and whirling vertigo, aural fullness, tinnitus and sudden hearing loss had commenced.

Otoscopic examination revealed a blood clot on the right tympanic membrane with granulation myringitis. A spontaneous and gaze nystagmus test was normal. Pure tone audiometry revealed sensorineural hearing loss of the right ear, with an average threshold above $48 \mathrm{~dB}$ (Fig. 1B). High resoluction temporal bone CT scans showed soft tissue density around the oval window, suggesting a PLF (Fig. 2C). The patient was admitted and treated conservatively for pneumolabyrinth, including high-dose steroid and absolute bed rest for 7 days. During her admission period, both vertigo and tinnitus improved but her hearing showed only a slight improvement with a threshold of about $33 \mathrm{~dB}$. She was discharged after 7 days of treatment. After 2 months, follow-up high resoluction temporal bone CT of the temporal bone (Fig. 2D) showed that the soft tissue density around the oval window had disappeared and her hearing impairment had fully recovered with a threshold of $5 \mathrm{~dB}$ (Fig. 1B).

\section{Case 3}

A 51-year-old male patient consulted our department with left-sided sudden hearing loss. The symptom had occurred 5 days after excessive sneezing, and the patient had constant tinnitus and fullness of his ears. Otoscopic examination showed that both eardrums were normal. Pure tone audiometry indicated left-sided sensorineural hearing loss with an air conduction threshold of $31 \mathrm{~dB}$ (Fig. 1C). A PLF was suspected, so a high resolution temporal bone CT scan was performed but the result was normal. However, based on the patient's clinical history, sensorineural hearing loss due to PLF was highly suggested. The patient was admitted, and high-dose steroid and broad-spectrum antibiotics were administered with bed rest. A gradual improvement in hearing was reported without other symptoms. Pure tone audiometry 14 days after admission showed an improvement in hearing with an air conduction threshold of $9 \mathrm{~dB}$ (Fig. 1C), and the patient was discharged.

\section{Discussion}

Middle ear surgery such as stapedectomy, or cholesteatoma removal from the oval and round windows may also cause a PLF. Patients with a PLF may suffer dizziness, nausea, vomiting, tinnitus, or hearing impairment. If patients experiencing these symptoms have a history of head trauma or middle ear surgery, this should increase suspicion for a PLF.

Although the exact mechanism of PLF formation is still uncertain, the most widely accepted route is the "implosive" and "explosive" theory suggested by Goodhill." The "explosive" mechanism occurs when there is an increase in CSF pressure which is transmitted from the internal auditory meatus or by the cochlear aqueduct. This mechanism suggests that an increased force in an abnormally patent cochlear aqueduct could rupture the basilar membrane and Reisner's membrane into

Table 1. Diagram of each cases

\begin{tabular}{|c|c|c|c|}
\hline & Case 1 & Case 2 & Case 3 \\
\hline A. Hospital visit day & 2 days after $N B$ & 6 days after $N B$ & 5 days after $N B$ \\
\hline B. Associated symptoms & $\begin{array}{l}\text { Hearing loss } \\
\text { Vertigo } \\
\text { Nausea } \\
\text { Vomiting }\end{array}$ & $\begin{array}{l}\text { Hearing loss } \\
\text { Vertigo } \\
\text { Aural fullness } \\
\text { Tinnitus }\end{array}$ & $\begin{array}{l}\text { Hearing loss } \\
\text { Tinnitus }\end{array}$ \\
\hline C. Temporal CT & $\begin{array}{l}\text { Multiple air pockets } \\
\text { in the vestibule }\end{array}$ & $\begin{array}{l}\text { Soft tissue density around } \\
\text { the oval window }\end{array}$ & Normal \\
\hline D. Follow up temporal CT & $\begin{array}{l}\text { After } 8 \text { days of admission, } \\
\text { multiple air pockets } \\
\text { disappeared }\end{array}$ & $\begin{array}{l}\text { After } 2 \text { months of outpatient } \\
\text { follow-up, soft tissue density } \\
\text { was not found }\end{array}$ & Not performed \\
\hline E. Dizziness improvement period & 8 days after admission & 2 days after admission & No subjective symptom \\
\hline F. Tinnitus improvement period & No subjective symptom & 4 days after admission & 5 days after admission \\
\hline $\begin{array}{l}\text { G. Complete restored hearing loss } \\
\text { period }\end{array}$ & 8 days after admission & 2 months after outpatient follow-up & 5 days after admission \\
\hline
\end{tabular}


the scala vestibuli, and consequently the transmitted force could injure the utricle, saccule, the semicircular canals, the round window membrane, or the annular ligament of the stapes. On the other hand, the "implosive" mechanism would be caused by a Valsalva maneuver, prolonged coughing or nose blowing resulting in a sudden increase in air pressure through the eustachian tube. This sudden increase in pressure in the middle ear cavity would cause rupture of the round window membrane or the annular ligament of the stapes.

Several studies have tried to determine the pressure change across the cochlear membrane and the middle ear pressure, which may be one of the main causes of spontaneous PLF and pneumolabyrinth. Yanagihara, et al. ${ }^{3,4)}$ reported a case of pneumolabyrinth induced after air inflation of the eustachian tube, suggesting that air entered the inner ear space through a PLF. The authors reported that the opening pressure of the eustachian tube after a Valsalva maneuver ranged between 250 and $650 \mathrm{mmH}_{2} \mathrm{O}$, which may create a positive middle ear pressure from 200 to $400 \mathrm{mmH}_{2} \mathrm{O}$. Air inflation of the eustachian tube or a Valsalva maneuver would also increase middle ear pressure to such an extent that it may lead to a PLF which consequently caused pneumolabyrinth. This is the "implosive" route of PLF formation. There is also a report focusing on the "explosive" route of PLF and pneumolabyrinth. In three patients with tympanic membrane rupture, Sakikawa, et al." used tympanometry with an earplug in the affected ear to measure the changes in CSF and middle ear pressure after nose blowing. They found that nose blowing increased not only middle ear pressure but also CSF pressure to an even greater extent. The mean value of maximum CSF pressure after nose blowing was $388 \mathrm{mmH}_{2} \mathrm{O}$, and the maximum middle ear pressure was $252 \mathrm{mmH}_{2} \mathrm{O}$. That study indicated that nose blowing may cause an outward pressure of more than $130 \mathrm{mmH}_{2} \mathrm{O}$ across the cochlear window.

Although PLF is not easy to identify through radiology, pneumolabyrinth can easily be diagnosed by temporal bone high resoluction temporal bone CT. It is not clear that all PLF is accompanied with pneumolabyrinth, but we can assume in our case 3, the patient was highly suspected of having pneumolabyrinth based on clinical history, even though there was no air pockets in the inner ear. The CT scan was performed several days after the initial symptoms, so the air may have been absorbed and dissipated. So doctors dealing with patients having symptoms of PLF should be aware that air is not always visible in the CT scan, especially if the scan is delayed, so PLF should not be ruled out even with negative findings from radiology. ${ }^{8)}$

There is no consensus on the management of pneumolabyrinth. The treatment options are observation or explorative tympanotomy. ${ }^{7)}$ Conservative management of pneumolabyrinth includes bed rest, head elevation, and avoidance of the Valsalva maneuver and physical exertion which raises intraabdominal pressure. Surgical exploration may occasionally be required in the management of displaced stapes, of progressive, fluctuating sensorineural hearing loss, or of persistent vertigo. ${ }^{2,9)}$

Timing of surgical exploration and repair of PLF has received considerable attention, therefore we suggest treatment guidelines for PLF.

Explorative tympanotomy should be performed to the patients with confirmed severe to profound sensorineural hearing loss over $70 \mathrm{~dB}$, and patients who had no clinical improvement even though 1-3 weeks of conservative treatment. ${ }^{8,10)}$

In our cases, all patients had hearing loss with mild to moderate degree and conservative management was chosen with injection of systemic steroids, and the symptoms in all patients improved after about a week.

In conclusion, high resoluction temporal bone $\mathrm{CT}$ of the temporal bone is useful for diagnosing pneumolabyrinth and PLF. Clinical symptoms are as important as temporal bone CT for diagnosing pneumolabyrinth and PLF when the air bubble or fistula is absorbed due to delayed examination.

Initial management of pneumolabyrinth-associated PLF is conservative treatment including intravenous steroids, absolute bed rest, head elevation. Exploratory tympanotomy should be performed when severe to profound sensorineural hearing was found or when there is no effect of 1-3 weeks of conservative treatment.

\section{Acknowledgments}

None.

\section{Author Contribution}

Writing - original draft: Ji Hoon Koh. Writing_review \& editing: Eun Jung Lee.

\section{ORCIDs}

Eun Jung Lee

https://orcid.org/0000-0001-6958-0312

Ji Hoon Koh

https://orcid.org/0000-0002-6749-6966

\section{REFERENCES}

1) Lee JS, Kwon SY, Kim JH, Kim HJ. Bilateral sequential pneumolabyrinth resulting from nose blowing. J Audiol Otol 2015;19(3):182-5.

2) Hornibrook J. Perilymph fistula: Fifty years of controversy. ISRN 
Otolaryngol 2012;2012:281248.

3) Yanagihara N, Hyodo J, Takagi D, Miuchi S. A case of pneumolabyrinth induced by Eustachian tube air inflation. Otol Neurotol 2012;33(8):1408-11.

4) Yanagihara N, Nishioka I. Pneumolabyrinth in perilymphatic fistula: Report of three cases. Am J Otol 1987;8(4):313-8.

5) Sakikawa Y, Kobayashi H, Nomura Y. Changes in middle ear pressure in daily life. Laryngoscope 1995;105(12 Pt 1):1353-7.

6) Lee EJ, Yang YS, Yoon YJ. Case of bilateral pneumolabyrinth presenting as sudden, bilateral deafness, without temporal bone fracture, after a fall. J Laryngol Otol 2012;126(7):717-20.

7) Woo HJ, Song SY, Kim YD, Bai CH. Pneumolabyrinth without temporal bone fracture: Different outcomes for hearing recovery. Laryngoscope 2008;118(8):1464-6.

8) Prenzler NK, Schwab B, Kaplan DM, El-Saied S. The role of explorative tympanotomy in patients with sudden sensorineural hearing loss with and without perilymphatic fistula. Am J Otolaryngol 2018;39(1):46-9.

9) Stroud MH, Calcaterra TC. Spontaneous perilymph fistulas. Laryngoscope 1970;80(3):479-87.

10) Elliott EJ, Smart DR. The assessment and management of inner ear barotrauma in divers and recommendations for returning to diving. Diving Hyperb Med 2014;44(4):208-22. 